\title{
KNOWLEDGE AND PRACTICE OF CAREGIVERS ABOUT PREVENTION OF EARLY CHILDHOOD CARIES
}

\author{
Rabaa Mahmoud Aboubakr* and Rasha Ibrahim Ramadan**
}

\begin{abstract}
Aim: This study was conducted to assess level of knowledge and practice of caregivers regarding prevention of early childhood caries in preschool children.

Methods: A cross-sectional study was conducted among caregivers of preschool children. Aconsecutive sampling technique was used to recruit 399 caregivers based on sample size calculation. Data was collected based on clinical examination and previously validated questionnaires. Dental caries experiences were calculated by dmft index using WHO criteria for dental caries diagnosis. Statistical analysis: Data was statistically analyzed using the Statistical Package of Social Science Software program, version 23. Data presented using frequency and percentage for qualitative variables. Comparison between groups had been performed using Chi-square or Fisher's exact test for qualitative variables. P- Values less than 0.05 were considered statistically significant.

Results: This study highlights that caregivers who have good knowledge about oral health are mothers, high level of education, high family income, caregivers of child with $\mathrm{dmft}<7$. Additionally, family with high income, caregivers of children aged $<4$ years and caregivers of the children with $\mathrm{dmft}<7$ and caregivers with sufficient knowledge each has higher practice regarding children oral health

Conclusion: the majority of caregivers $(64.4 \%$.) had sufficient knowledge related to prevention of ECC. In spite of that most of them $(63.2 \%)$ were having low skills to prevent ECC . So, oral health education programs should be targeted to caregivers especially the lower socio-economic groups to motivate them to take care of their child oral health and improve their practice..
\end{abstract}

KEYWORDS: Knowledge, Practice, Early childhood caries, Caregivers, Egypt

* Assistant Professor of Dental Public Health and Preventive Dentistry, Department of Pediatric Dentistry and Dental Public Health, Mansoura University.

** Lecturer of Dental Public Health and Preventive Dentistry, Department of Pediatric Dentistry and Dental Public Health, Mansoura University. 


\section{INTRODUCTION}

Early childhood caries (ECC) can be defined as the presence of one or more decayed, missing, or filled tooth surface in any primary tooth in a child aged 71 months or younger ${ }^{(1)}$. The prevalence of ECC was widely varied to range from $6-90 \%$ (2). Due to this high prevalence and its influence on child's quality of life, it was categorized as a serious community health problem ${ }^{(3)}$.

It is well known that ECC is a multifactorial disease, as several factors play important roles in its etiology like; breast feeding for long period, prolonged or frequent bottle feeding, number of family members or the child's birth order, dietary habits, and timing or reasons for child's first dental visit, oral hygiene practices ${ }^{(4,5)}$. Also oral health knowledge and attitude of parents have great influence on their children's oral health ${ }^{(6,7)}$. Parents with good oral health knowledge and attitude have positive effect on their children's oral health ${ }^{(8-11)}$.

Infants with early childhood caries (ECC) can suffer from dental infections and pain which results in difficulties in eating, sleeping, and missing school days, also problems like psychosocial, stunted growth, and the increased possibility of caries in permanent teeth ${ }^{(12,13)}$. Those affected children can suffer from low self-esteem, which adversely affect their well-being and oral health-related quality of life (OHQoL) ${ }^{(14,15)}$.

It is difficult to treat ECC as it is costly and takes up time of the child and caretakers ${ }^{(16,17)}$. Also the majority of dentists are not trained to manage young children ${ }^{(17)}$. In some cases, general anesthesia may be the only way to treatment and there is high rates of recurrent caries thus requiring retreatment ${ }^{(18)}$. Hence dental professions prefer preventive approaches to manage ECC ${ }^{(19)}$. Preventive programs of ECC are found in several countries and most of them aim at training parents to recognize ECC at early stage and search for treatment ${ }^{(20)}$.
Low level of caries prevalence was reported in children from parents with high level of education and socioeconomic status ${ }^{(21)}$. Unemployed parents that are low educated and has low income have poor health and chronic diseases ${ }^{(22)}$. Knowledge, attitude, and preventive practices of parents/caregivers play a major role in a child's life, as parents' knowledge of oral health is an important contributing factor to the overall health of the child ${ }^{(23)}$.

The main risk factors of severs early childhood caries (S-ECC) were identified as following: the level of education of fathers and /or mothers, child's dietary habits, oral hygiene practice in addition to child dental visits can ${ }^{(24)}$.

Several studies were carried out to explore knowledge and practice of caregivers on prevention of ECC ${ }^{(25-29)}$. At (2012) Shani et al ${ }^{(25)}$, cleared that parents had good knowledge but poor attitude and practice towards their children's oral health. They also concluded that knowledge is not necessarily translated into good practices. Additionally; Abu Hamila (2013) ${ }^{(26)}$ reported that, the most important determinant of ECC are; the educational level, employment status, oral hygiene practice and attitude of mothers in maintaining oral hygiene of their children. In addition to this, child's position in the family, type of feeding and oral hygiene practice were also dependently associated with ECC.

Also at (2016) another study was performed in Sudan ${ }^{(27)}$ to assess the mother's dental health knowledge and practice in regards to their age, education and occupation. Their results cleared a relatively good mother's knowledge about dental health of preschool children, but at the same time this knowledge was not fully reflected on practices. Then at $(2018)^{(28,29)}$, two studies were performed in Saudi Arabia to measure parent's knowledge, attitude and practice to prevent ECC. Both studies revealed insufficient knowledge of the parents regarding their children oral health and hygiene. 
Prevention is the key for ECC that can be achieved through knowledgeable and efficacious caregivers. Prevention of ECC depends mainly on educating parents and primary caregivers about ECC. It is essential to explore the knowledge, attitude, and preventive practice of parents/caregivers as it affects children's dental care and the prevention of ECC ${ }^{(20)}$. So, it is worthy to assess knowledge of caregivers about prevention of early childhood caries as it plays the main role in prevention of ECC among preschool children. From this point of view this study was performed aiming to assess knowledge and practice among a group of caregivers in Egypt.

\section{SUBJECTS AND METHODS}

\section{Study Design and location}

This descriptive cross-sectional study was carried out in the Pediatric Dental Clinic, Faculty of Dentistry, Mansoura University.

\section{Sampling size and technique}

A consecutive sampling technique was used in which every subject met the inclusion criteria was selected until the required sample size was achieved $^{(30)}$. Sample size was estimated to be 385 child based on the following assumptions; confidence level 95\%, confidence interval 5\%, population proportion $50 \%$ (https://www.calculator. net/sample-size-). This number was increased to be 400 in order to compensate missed data.

\section{Inclusion and exclusion criteria}

Children of both genders with age ranged from 3-6 years and free from systemic diseases and whose mothers accepted to participate in the study were included. While children with serious medical conditions or who came to the clinic with caregivers who cannot give the required information were excluded from the study.

\section{Ethical approval}

This study was performed after approval of Ethical Committee, Faculty of Dentistry, Mansoura University. Informed consents were collected from participating caregivers after brief explanation of the study and its purposes to them.

\section{Data collection}

Data was collected through questionnaires and clinical examinations.

\section{Clinical examination}

The selected children were examined in the pediatric dental clinic on dental units using reusable sterilized examination kits. World Health Organization (WHO) $)^{(31)}$ diagnostic criteria was used to differentiate between caries affected and caries free children. According to the American Academy of Pediatric Dentistry (AAPD) ${ }^{(32)}$, children were considered to be suffering from ECC if there is one or more decayed, missing or filled tooth surfaces in any primary tooth in a child of 71 months of age or younger. The children were asked about presence or absence of pain before the examination. Dental caries was measured using dmft index. The patients were scored into those with dmft value less than 7 , between 7 and 13, or equal to or more than 14 .

\section{Data collection through questionnaires}

Pretested well-structured close ended questionnaires were prepared according to Wilson et al 2016 (The Cronbach alpha for the oral health knowledge scale was 0.51 and for behavior $0.55)^{(33)}$. Appropriate changes were done to make all the statements comprehensible to caregivers. They had the choice to accept or not to answer some questions like number of children in the family or income.

The questionnaire was divided into 4 parts; part I was about caregivers' sociodemographic characters 
(relation to child, educational level, family income, and marital status), part II was about child characters (gender, age, race, dental insurance status). Part III was used to measure caregivers' literacy level which was assessed through knowledge of parents about prevention of ECC and their skills in prevention.

At the beginning all children were examined in the pediatric clinics, and the mothers whose children had ECC were selected to fill in the questionnaires. Questionnaires were not translated into Arabic as the examiner himself was present with the participants to explain the questionnaire items in their native language.

\section{Statistical analysis}

Data were analyzed using SPSS (Statistical Package for Social Science) software program. Descriptive statistics were used for frequency tables. Multiple regression analysis were used to significantly correlate determinants of knowledge and practice. Levels of significance concerning knowledge (sufficient or insufficient) and practice (high or low) and their association to the questionnaire items were tested using chi-square test. All significant relations were kept at $(\mathrm{p}<0.05)$. Comparison between means of practice and knowledge was done by independent sample t-test.

\section{RESULTS}

Table (1) illustrates the following data; the majority of caregivers who accompanied the participating children were mothers (70.4\%). Concerning educational levels of caregivers; the higher percentage of participants were having college degrees (42.9\%). Regarding family income, $39.3 \%$ of the participants refused to clear their incomes, while $34.6 \%$ of them were having 20004000 L.E per month. Also about $86.2 \%$ of the participants were married.
TABLE (1): Distribution of Demographic Characteristics of Caregivers

\begin{tabular}{|c|c|}
\hline Caregivers Characteristics & $\begin{array}{c}\text { Number }(\%) \\
(n=399)\end{array}$ \\
\hline \multicolumn{2}{|l|}{ Relation to the child } \\
\hline Father & $90(22.6)$ \\
\hline Mother & $281(70.4)$ \\
\hline Grandmother & $9(2.3)$ \\
\hline Other & $19(4.8)$ \\
\hline \multicolumn{2}{|l|}{ Education level } \\
\hline Less than high school & $59(14.8)$ \\
\hline High school & $156(39.1)$ \\
\hline College degree & $171(42.9)$ \\
\hline Higher than college degree & $13(3.3)$ \\
\hline \multicolumn{2}{|l|}{ Family income } \\
\hline$<2000$ L.E & $29(7.3)$ \\
\hline 2000-4000 L.E & $138(34.6)$ \\
\hline >4000L.E & $75(18.8)$ \\
\hline I do not know & $157(39.3)$ \\
\hline \multicolumn{2}{|l|}{ Marital status } \\
\hline Married & $344(86.2)$ \\
\hline Divorced & $42(10.5)$ \\
\hline Single & $12(3)$ \\
\hline Others & $1(0.3)$ \\
\hline
\end{tabular}

Demographic characteristics of children was shown in table (2), according to this table the participating males were greater than females (55.1\% vs $44.9 \%)$. Also $43.4 \%$ of participating children were having ages from 4-5 years old, and $38.6 \%$ of them were $5-6$ years old, while $18 \%$ were 3-4 years old. Regarding dental insurance coverage $71.2 \%$ were covered and $28.8 \%$ were uncovered with it. 
TABLE (2): Distribution of Demographic Characteristics of participating children

\begin{tabular}{|c|c|}
\hline Child demographic data & $\begin{array}{c}\text { Number }(\%) \\
(n=399)\end{array}$ \\
\hline \multicolumn{2}{|l|}{ Gender } \\
\hline Male & $220(55.1)$ \\
\hline Female & $179(44.9)$ \\
\hline \multicolumn{2}{|l|}{ Age } \\
\hline 3-4 years & $72(18)$ \\
\hline $4-5$ years & $173(43.4)$ \\
\hline 5-6 years & $154(38.6)$ \\
\hline \multicolumn{2}{|l|}{ Dental insurance } \\
\hline Yes & $284(71.2)$ \\
\hline No & $115(28.8)$ \\
\hline
\end{tabular}

Table (3) illustrates caregiver's knowledge about prevention of ECC. About $92.5 \%$ of the caregivers considered oral health as an important issue. Also the majority of them $97.7 \%$ considered dental caries as a preventable problem and $70.2 \%$ thought that fluoride can prevent dental caries. Also most of the caregivers were against eating before bed, eating chips, drinking soda, sharing toothbrush or spoon with children $(85.7 \%, 95.7 \%, 92.7 \%, 90.7 \%$, and $78.9 \%$ respectively). We can conclude that the majority of caregivers had sufficient knowledge of $64.4 \%$.

TABLE (3): Caregivers' Knowledge about Prevention of Early Childhood Caries

\begin{tabular}{|c|c|}
\hline Knowledge Items & $\begin{array}{c}\text { Number }(\%) \\
(n=399)\end{array}$ \\
\hline \multicolumn{2}{|l|}{ Is oral health an important issue? } \\
\hline Yes & $369(92.5)$ \\
\hline No & $30(7.5)$ \\
\hline \multicolumn{2}{|l|}{ Can dental caries be prevented? } \\
\hline Yes & $318(79.7)$ \\
\hline No & $81(20.3)$ \\
\hline \multicolumn{2}{|l|}{ If fluorides can prevent dental caries? } \\
\hline Yes & $280(70.2)$ \\
\hline No & $119(29.8)$ \\
\hline \multicolumn{2}{|c|}{ Deciduous teeth are not important, as they present for limited period } \\
\hline True & $110(27.6)$ \\
\hline False & $289(72.4)$ \\
\hline \multicolumn{2}{|c|}{ No necessary to go to the dentist unless children have dental complain } \\
\hline True & $195(48.9)$ \\
\hline False & $204(51.1)$ \\
\hline \multicolumn{2}{|c|}{ Fluoridated Toothpaste should be used to brush your child's teeth } \\
\hline True & $250(62.7)$ \\
\hline False & $149(37.3)$ \\
\hline \multicolumn{2}{|l|}{ Tooth decays occurred by microorganisms in the oral cavity } \\
\hline True & $288(72.2)$ \\
\hline False & $111(27.8)$ \\
\hline \multicolumn{2}{|c|}{ Eating anything after brushing child's teeth but before going to bed } \\
\hline True & $57(14.3)$ \\
\hline False & $342(85.7)$ \\
\hline \multicolumn{2}{|l|}{ Eating chips } \\
\hline Good & $17(4.3)$ \\
\hline Bad & $382(95.7)$ \\
\hline
\end{tabular}




\begin{tabular}{|l|c|}
\hline Drinking soda or pop & \\
\hline Good & $29(7.3)$ \\
\hline Bad & $370(92.7)$ \\
\hline Sharing your toothbrush with your child & $37(9.3)$ \\
\hline Good & $362(90.7)$ \\
\hline Bad & \\
\hline Using the your child's spoon to taste the food and feed the child & $84(21.1)$ \\
\hline Good & $315(78.9)$ \\
\hline Bad & \\
\hline Putting fluoride varnish on your child's teeth & $278(69.7)$ \\
\hline Good & $121(30.3)$ \\
\hline Bad & $361(90.5)$ \\
\hline Checking your child's teeth every month for changes or spots & $38(9.5)$ \\
\hline Good & \\
\hline Bad & $21.4-100$ \\
\hline Knowledge \% score & $78.9 \pm 17.6$ \\
\hline Range & $78.6(71.4-92.9)$ \\
\hline Mean $\pm S D$ & \\
\hline Median $(I Q R)$ & $257(64.4)$ \\
\hline Knowledge & $142(35.6)$ \\
\hline Sufficient $(\geq 75 \%)$ & \\
\hline Insufficient $(<75 \%)$ & \\
\hline
\end{tabular}

Table (4) explores caregiver's practice to prevent ECC. 37.3\% of caregivers were cleaning their infant mouths by water rinsing after meals, and $66.7 \%$ did not visit the dentist for children routine checkup last year. $88 \%$ of them first go for dental care after the age of 1 year. Majority of children $63.4 \%$ brushed their teeth once/day, while $63.9 \%$ of them brushed teeth before going to bed 0-3 times in the past week, $72.2 \%$ received parental help in brushing their teeth, $38.3 \%$ were eating sweet < once/day. $63.2 \%$ of parents were having low skills to prevent ECC.

TABLE (4): Caregivers' practice for prevention of early childhood caries

\begin{tabular}{|l|c|}
\hline \multicolumn{1}{|c|}{ Practice items } & $\begin{array}{c}\text { Number (\%) } \\
(\mathbf{n = 3 9 9 )}\end{array}$ \\
\hline How to routinely clean the infant's mouth? & $135(33.8)$ \\
Dental brush alone & $66(16.5)$ \\
Brush and floss & $149(37.3)$ \\
Make him to rinse after meals & $49(12.3)$ \\
Others & \\
\hline In the last year, has your child visited the dentist for a routine checkup or cleaning? & $133(33.3)$ \\
Yes & $266(66.7)$ \\
No & \\
\hline How old was your child during first dental visit for dental care? & $48(12)$ \\
<1 year & $351(88)$ \\
\hline 1 year & \\
\hline
\end{tabular}




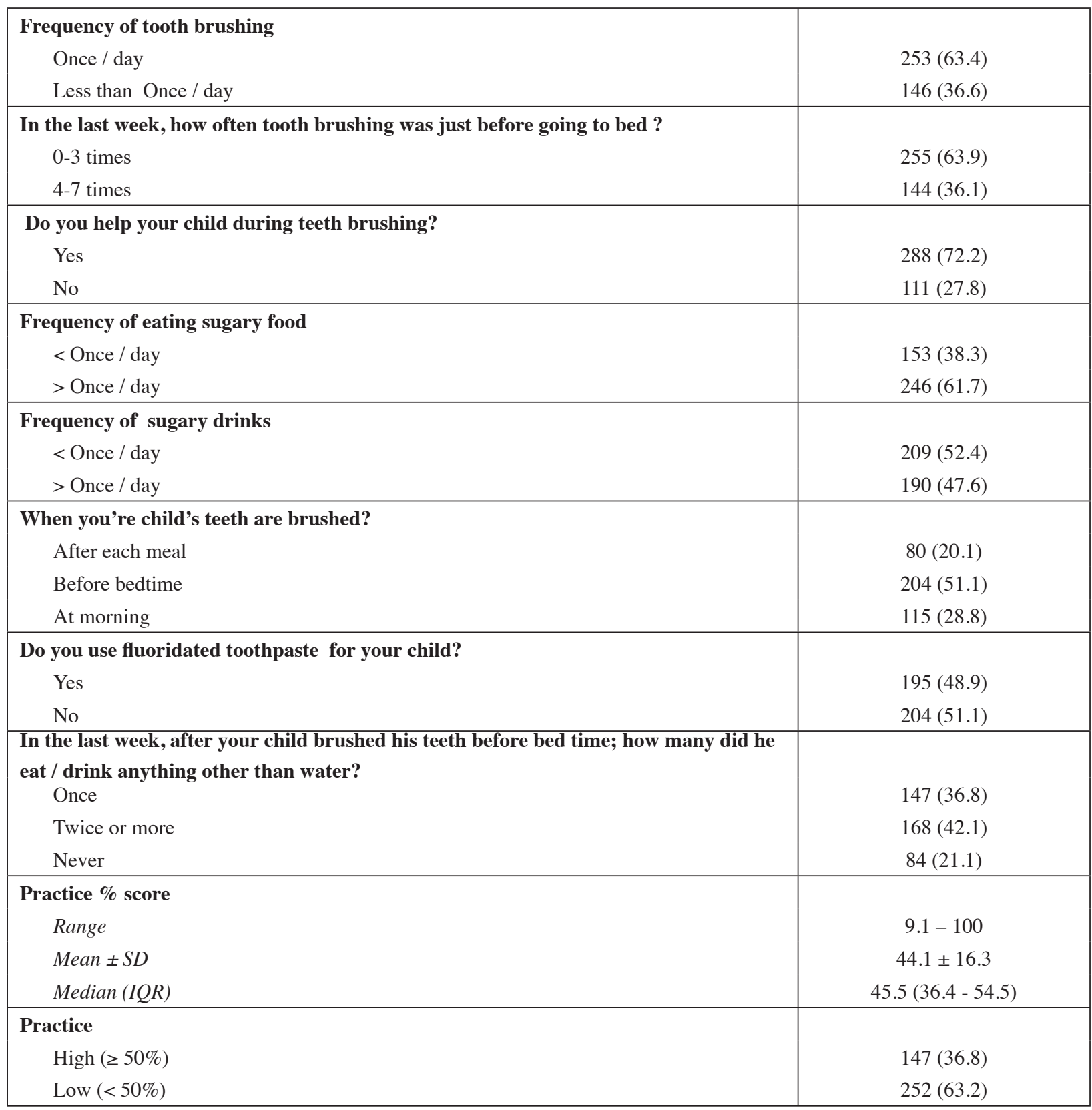

\section{SD: standard deviation}

Table (5) shows Determinants of Knowledge about Early Childhood Caries. Concerning to caregivers' relations to the children; mothers have the highest odds to be knowledgeable (adjusted $\mathrm{OR}=1.947,95 \% \mathrm{CI}=1.252-3.027$ ). However for the relation of knowledge to educational levels, those with college degree had higher odds (adjusted $\mathrm{OR}=1.884$, 95\% $\mathrm{CI}=1.23 \quad$ - 2.887). For family income, those with higher family income $>4000$ L.E were having higher odds (adjusted $\mathrm{OR}=2.143$, 95\% $\mathrm{CI}=1.194-3.847$ ). As regards to marital status, caregivers who are in stable families were having higher knowledge (adjusted $\mathrm{OR}=2.092$, 95\% CI=1.178 - 3.716). Lastly, caregivers of child with dental caries experience less than 7 have better knowledge (OR=1.912 95\% CI=1.155 - 3.165) 
TABLE (5): Determinants of Knowledge about Early Childhood Caries

\begin{tabular}{|c|c|c|c|c|}
\hline & \multicolumn{2}{|c|}{ Knowledge } & \multirow{2}{*}{$\begin{array}{c}\mathrm{X}^{2} \text { test } \\
\text { P value }\end{array}$} & \multirow[b]{2}{*}{ OR $(95 \% \mathrm{CI})$} \\
\hline & Sufficient & Insufficient & & \\
\hline \multicolumn{5}{|l|}{ Relation to the child } \\
\hline Father & $50(19.5)$ & $40(28.2)$ & $0.046^{*}$ & $0.616(0.382-0.994)$ \\
\hline Mother & $194(75.5)$ & $87(61.3)$ & $0.003 *$ & $1.947(1.252-3.027)$ \\
\hline Grandmother & $3(1.2)$ & $6(4.2)$ & 0.074 & $0.268(0.066-1.087)$ \\
\hline Other & $10(3.9)$ & $9(6.3)$ & 0.272 & $0.598(0.237-1.509)$ \\
\hline \multicolumn{5}{|l|}{ Education level } \\
\hline Less than high school & $25(9.7)$ & $34(23.9)$ & $<0.001 * *$ & $0.342(0.195-0.602)$ \\
\hline High school & $99(38.5)$ & $57(40.1)$ & 0.751 & $0.934(0.614-1.421)$ \\
\hline College degree & $124(48.2)$ & $47(33.1)$ & $0.003^{*}$ & $1.884(1.23-2.887)$ \\
\hline Higher than college degree & $9(3.5)$ & $4(2.8)$ & 0.712 & $1.252(0.379-4.14)$ \\
\hline \multicolumn{5}{|l|}{ Family income } \\
\hline$<3000$ & $12(4.7)$ & $17(12)$ & $0.007 *$ & $0.36(0.167-0.778)$ \\
\hline $3000-7000$ & $78(30.4)$ & $60(42.3)$ & $0.017 *$ & $0.596(0.389-0.912)$ \\
\hline$>7000$ & $58(22.6)$ & $17(12)$ & $0.009 *$ & $2.143(1.194-3.847)$ \\
\hline I do not know & $109(42.4)$ & $48(33.8)$ & 0.092 & $1.442(0.941-2.21)$ \\
\hline \multicolumn{5}{|l|}{ Marital status } \\
\hline Married & $230(89.5)$ & $114(80.3)$ & $0.011 *$ & $2.092(1.178-3.716)$ \\
\hline Divorced & $18(7)$ & $24(16.9)$ & $0.002 *$ & $0.37(0.193-0.709)$ \\
\hline Single & $9(3.5)$ & $3(2.1)$ & 0.551 & $1.681(0.448-6.314)$ \\
\hline Others & $0(0)$ & $1(0.7)$ & 0.356 & NA \\
\hline \multicolumn{5}{|l|}{ Gender } \\
\hline Male & $142(55.3)$ & $78(54.9)$ & 0.950 & $1.013(0.671-1.53)$ \\
\hline Female & $115(44.7)$ & $64(45.1)$ & & \\
\hline \multicolumn{5}{|l|}{ Age } \\
\hline $3-4$ years & $48(18.7)$ & $24(16.9)$ & 0.659 & $1.129(0.658-1.937)$ \\
\hline $4-5$ years & $108(42)$ & $65(45.8)$ & 0.469 & $0.859(0.568-1.297)$ \\
\hline $5-6$ years & $101(39.3)$ & $53(37.3)$ & 0.698 & $1.087(0.713-1.658)$ \\
\hline \multicolumn{4}{|l|}{ Dental insurance } & \\
\hline Yes & $188(73.2)$ & $96(67.6)$ & 0.242 & $1.306(0.835-2.041)$ \\
\hline No & $69(26.8)$ & $46(32.4)$ & & \\
\hline \multicolumn{5}{|l|}{ Dmft } \\
\hline$<7$ & $217(84.4)$ & $105(73.9)$ & $0.011 *$ & $1.912(1.155-3.165)$ \\
\hline $7-13$ & $39(15.2)$ & $35(24.6)$ & $0.020 *$ & $0.547(0.328-0.912)$ \\
\hline$\geq 14$ & $1(0.4)$ & $2(1.4)$ & 0.289 & $0.273(0.025-3.042)$ \\
\hline
\end{tabular}

${ }^{*}$ Chi-square test at $p<0.05, *$ *Chi-square test at $p<0.001, \mathrm{OR}=$ odds ratio, $\mathrm{CI}=$ confidence interval, 
Table (6) shows determinant of caregivers' practice about ECC. It was found that families whose income exceeded 4000 LE had better practice to prevent ECC among their children $(\mathrm{OR}=$ 2.843, at confidence (1.701-4.751) and caregivers who are in stable families were having higher practice $(\mathrm{OR}=2.615$, at confidence $(1.305-5.241)$. Concerning to the children age, caregivers of children aged from 3-4 years old were having higher practice $(\mathrm{OR}=2.085$, at confidence (1.245-3.494). regarding to caries experience of the children, caregivers of children with caries experience less than 7 teeth have better skills to prevent ECC
$(\mathrm{OR}=2.615$, at confidence (1.444-4.735). In addition to that; it was found that caregivers with sufficient knowledge to prevent ECC have also better practice to prevent ECC

Table (7) shows the clinical findings of children. From this table we can conclude the following; the majority of children were having no pain (56.4\%), the majority of them had decayed teeth $62.9 \%$, while the minority were having missed teeth $26.8 \%$, and concerning dmft majority were have $<7$, followed by $7-13$, then $\geq 14(80.7 \%, 18.5 \%$, and $0.8 \%$ respectively).

TABLE (6): Determinants of Practice about Early Childhood Caries

\begin{tabular}{|c|c|c|c|c|}
\hline & \multicolumn{2}{|c|}{ Practice } & \multirow{2}{*}{$\begin{array}{c}\mathrm{X}^{2} \\
\text { Pvalue }\end{array}$} & \multirow[b]{2}{*}{ OR $(95 \% \mathrm{CI})$} \\
\hline & High & Low & & \\
\hline \multicolumn{5}{|l|}{ Relation to the child } \\
\hline Father & $39(26.5)$ & $51(20.2)$ & 0.147 & $1.423(0.882-2.295)$ \\
\hline Mother & $105(71.4)$ & $176(69.8)$ & 0.738 & $1.08(0.69-1.689)$ \\
\hline Grandmother & $0(0)$ & $9(3.6)$ & 0.029 & NA \\
\hline Other & $3(2)$ & $16(6.3)$ & 0.051 & $0.307(0.088-1.073)$ \\
\hline \multicolumn{5}{|l|}{ Education level } \\
\hline Less than high school & $17(11.6)$ & $42(16.7)$ & 0.166 & $0.654(0.357-1.197)$ \\
\hline High school & $52(35.4)$ & $104(41.3)$ & 0.244 & $0.779(0.511-1.187)$ \\
\hline College degree & $72(49)$ & $99(39.3)$ & 0.059 & $1.484(0.984-2.237)$ \\
\hline Higher than college degree & $6(4.1)$ & $7(2.8)$ & 0.562 & $1.489(0.491-4.519)$ \\
\hline \multicolumn{5}{|l|}{ Family income } \\
\hline$<2000$ & $17(11.6)$ & $12(4.8)$ & $0.012 *$ & $2.615(1.212-5.644)$ \\
\hline $2000-4000$ & $32(21.8)$ & $106(42.1)$ & $<0.001 * *$ & $0.383(0.241-0.61)$ \\
\hline$>4000$ & $43(29.3)$ & $32(12.7)$ & $<0.001 * *$ & $2.843(1.701-4.751)$ \\
\hline I do not know & $55(37.4)$ & $102(40.5)$ & 0.546 & $0.879(0.579-1.336)$ \\
\hline \multicolumn{5}{|l|}{ Marital status } \\
\hline Married & $136(92.5)$ & $208(82.5)$ & $0.005 *$ & $2.615(1.305-5.241)$ \\
\hline Divorced & $7(4.8)$ & $35(13.9)$ & $0.004 *$ & $0.31(0.134-0.717)$ \\
\hline Single & $3(2)$ & $9(3.6)$ & 0.547 & $0.563(0.15-2.112)$ \\
\hline Others & $1(0.7)$ & $0(0)$ & 0.368 & NA \\
\hline \multicolumn{4}{|l|}{ Gender } & \multirow{3}{*}{$0.998(0.663-1.502)$} \\
\hline Male & $81(55.1)$ & $139(55.2)$ & 0.991 & \\
\hline Female & $66(44.9)$ & $113(44.8)$ & & \\
\hline
\end{tabular}




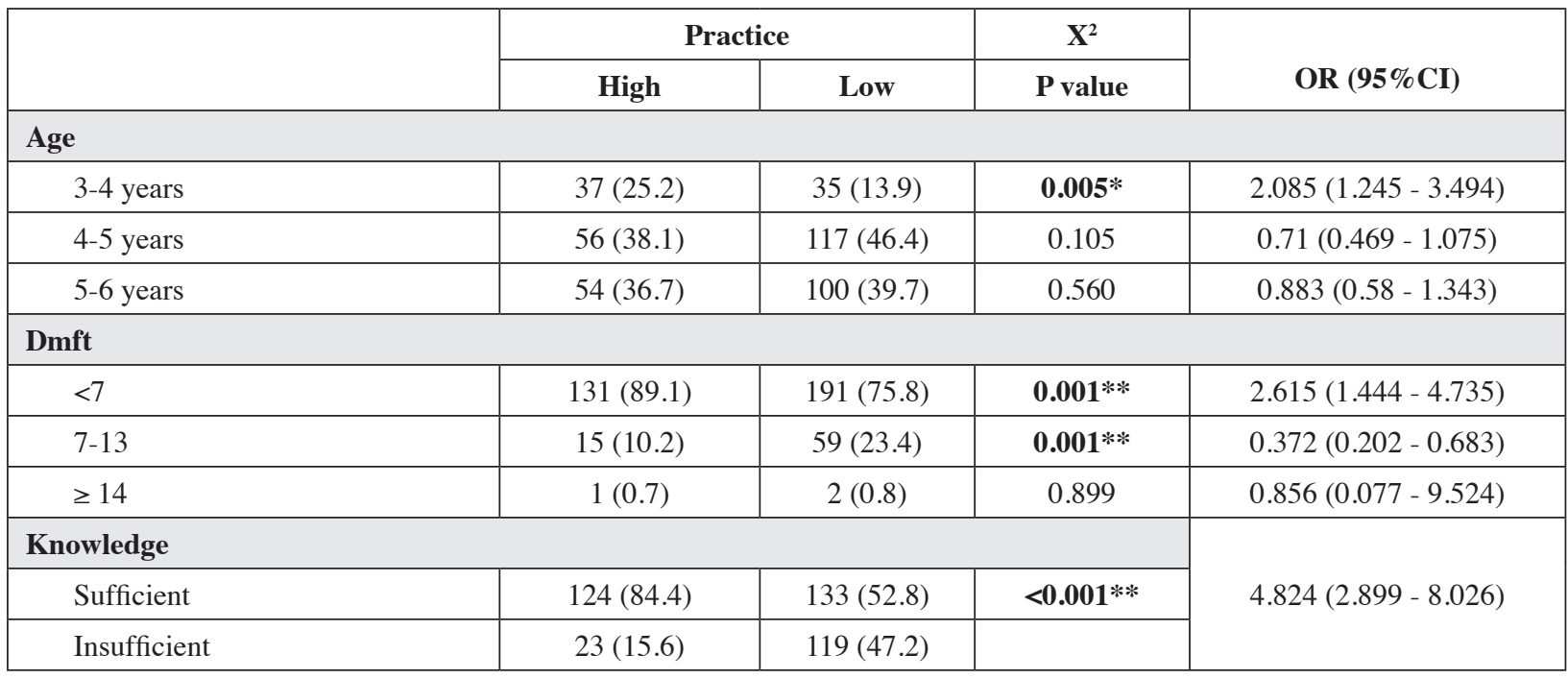

*Chi-square test, $\mathrm{OR}=$ odds ratio, $\mathrm{CI}=$ confidence interval,

NB Knowledge score was cut at level of $75 \%$ as knowledge questions were leading so most of cases obtained higher scores while Practice score was cut at $50 \%$ as the majority obtained low practice scores.

TABLE (7): Distribution of Pain and Dental Caries Experiences among Participating Children

\begin{tabular}{|c|c|}
\hline Clinical Findings & $\begin{array}{c}\text { Number (\%) } \\
(\mathbf{n = 3 9 9 )}\end{array}$ \\
\hline $\begin{array}{c}\text { Presence of pain } \\
\text { Yes }\end{array}$ & $174(43.6)$ \\
No & $225(56.4)$ \\
\hline Decayed teeth (dt) & \\
Yes & $251(62.9)$ \\
No & $148(37.1)$ \\
\hline Missed teeth (mt) & $107(26.8)$ \\
Yes & $292(73.2)$ \\
No & \\
\hline Filled teeth $(\mathbf{f t})$ & $183(45.9)$ \\
Yes & $216(54.1)$ \\
No & \\
\hline Dmft & $322(80.7)$ \\
$<7$ & $74(18.5)$ \\
$7-13$ & $3(0.8)$ \\
$\geq 14$ & \\
\hline
\end{tabular}




\section{DISCUSSION}

Oral health is a vital facet of general health in infants and children. This has an effect on the quality of life and health consequences. With regard to oral well-being caregivers are the earliest sources of education for children ${ }^{(12)}$, so assessing and subsequently improving the knowledge and awareness among parents and caregivers is a fundamental component in dental disease prevention in children below 6 years of age ${ }^{(34)}$.

Concerning to demographic distribution of caregivers and their children, the results of the present study revealed that, the majority of caregivers were mothers and that of children were boys with an age ranged from 4-6 years old. Concerning educational levels of caregivers; it was found that, the majority of participants were graduated from colleges. These results matched with Abduljalil, et al (2016) ${ }^{(27)}$; Hiu, et al (2017) ${ }^{(35)}$; Alzaidi, et al. (2018) ${ }^{(28)}$; Ravi, et al (2018) ${ }^{(29)}$.

Regarding to caregivers' knowledge to prevent ECC, our study revealed that, most of the caregivers had sufficient knowledge concerning to oral health, prevention of dental caries, and proper dietary habits. This high level of knowledge may be attributed to the participants' higher educational level $(45.2 \%)$. It is well known that, the better the level of the mothers education, the better knowledge they will have. ${ }^{(27)}$ In addition to that, the majority of the caregivers of the present study were mothers (70.4\%) who have high odds to be knowledgeable (adjusted $\mathrm{OR}=1.947$ ) especially the highly educated ones (adjusted OR=1.884).

These findings was in accordance with Man, et al (2012) ${ }^{(25)}$; Anne, et al.(2015) ${ }^{(36)}$; Kamil, et al. (215) ${ }^{(37)}$; Abduljalil, et al(2016) ${ }^{(27)}$ who concluded that mothers had sufficient knowledge related to oral hygiene practices and diet in addition to proper dietary practices . Mother's education was highly correlated to their dental health knowledge. Mothers with high educational level (a university level or higher) had significantly higher knowledge than those with low education level. Additionally, Rafi, et al. (2017) ${ }^{(38)}$; found that the majority of caregivers had proper information related to children's oral health.

The finding that, level of mother's education has direct relation to oral health was also proved by Alzaidi, et al (2018) ${ }^{(28)}$ who revealed that mothers with high level of education conveyed better knowledge about oral hygiene and oral health while illiterate mothers conveyed low level of knowledge. In contrary to that, Al-Zahrani, et al. (2014) (13) reported that, the mothers have incomplete knowledge and should receive health education programs in several important points such as diet, feeding practices and first visit to the dentist.

As regards to the caregiver's practice to prevent ECC, Majority of parents have low skills to prevent ECC (63.2\%) especially for, dental visit for routine chick up and tooth brushing. Although, the American Academic of Pediatric Dentistry (AAPD) recommended that "the first dental visit should be with the eruption of the first primary tooth and no later than twelve months of age ${ }^{(39)}$. The majority of our participants $88 \%$ didn't visit dentist until their children were older than one year and $66 \%$ of them didn't visit the dentist last year for regular checkup. This explored that most of care givers did not take their children to dentist unless there is pain or trouble. This could be attributed to lack of knowledge about the importance of regular dental attendance or limited financial resources.

These findings were in accordance with the findings of two studies carried out in India. As they revealed that, mothers had deficient practice at area of regular dental visit for routine chick up ${ }^{(40,41)}$. Also Al-Zahrani, et al (2014) ${ }^{(13)}$ reported that $66.7 \%$ of mothers accepted that a child should go to the dentist due to a dental pain/problem only. However, our findings were not in accordance with Schroth, et al (2007) ${ }^{11}$; Abduljalil, et al (2016) ${ }^{(27)}$ who reported good maternal knowledge about the ideal time for first dental visit. Also Rafi, et al. (2017) ${ }^{(38)}$ stated 
that $86.1 \%$ of their participants were aware that a child should visit the dentist regularly even if they have no teeth-related complaint.

Focusing on teeth brushing, it was found that majority of our caregivers supervise the child during brushing but brushing was not regularly before bed time and the child might eat after brushing in $78.9 \%$ of the participants. This improper brushing practice indicated that mothers have deficient practices to prevent dental caries. This result was in agreement with Kamil, et al (2015) ${ }^{(37)}$ who concluded that more than half of the participant mothers do not know the ideal time to begin cleaning of the child mouth. Similarly, Abduljalil et al (2016) ${ }^{(27)}$ showed relatively lower practice scores related to teeth brushing. Moreover Rafi, et al (2017) ${ }^{(38)}$ found that $45.2 \%$ of caregivers had never cleaned or brushed the child's teeth.

In spite of the relatively good dental health knowledge of our study, the knowledge has not been fully reflected into practice. This finding was consistent with several studies ${ }^{(27,33,42,43)}$. Additionally Rafi, et al. (2017) ${ }^{(38)}$ indicated that their study's participants were unable to translate their knowledge into everyday practice although the majority of them had proper knowledge related to the children's oral. In contrary to that Ravi et al (2018) ${ }^{(29)}$ reported that; the parents did not have adequate knowledge of ECC but did have a good attitude and practice towards its prevention.

Relating to clinical findings of our children; our result conclude that; more than half of the children didn't suffer from pain, and $62.9 \%$ of them had decayed teeth, and most of them had dmft value less than 7. This was in harmony with Abu Hamila $(2013)^{(26)}$ who diagnosed early childhood caries in $69.6 \%$ of the children, with mean $\mathrm{dmft}$ values ranged from (2.1-7.6). The author reported that; the high caries prevalence in the deciduous teeth necessitates instant consideration and he suggested that teeth examination should be obligatory and may be added to immunization schedule of child (an official form), this may have a role in prevention, early detection and treatment of ECC.

Furthermore, Hiu et al.(2017) ${ }^{(35)}$ found that most of the participant children had no pain $(71.1 \%)$ and $98.7 \%$ of them had unfilled dental caries. while the mean decayed, missing and filled teeth (dmft) score was 10.2 as the majority of the children had $\mathrm{dmft}$ from $7-13$ teeth. ${ }^{350}$

\section{RECOMMENDATIONS}

Planning for regular dental education programs for parents of preschool children is very important as mother's knowledge and practices related to oral health has vital role on the oral health of their children and quality of life. These dental education programs will improve their knowledge and practices that would help in the prevention of early childhood caries. Further studies with larger sample size and different areas in Egypt may give more representative results.

\section{ACKNOWLEDGEMENT}

The authors gratefully acknowledge all the mothers participated in the study for their cooperation

\section{REFERENCES}

1. Drury TF, Horowitz AM, Ismail AI, Maertens MP, Rozier RG, Selwitz RH. Diagnosing and reporting early childhood caries for research purposes. A report of a workshop sponsored by the National Institute of Dental and Craniofacial Research, the Health Resources and Services Administration, and the Health Care Financing Administration. J Public Health Dent 1999; 59(3):192-7. doi: 10.1111/j.1752-7325.1999.tb03268.x.

2. O’Mullane D, Parnell C. Early childhood caries: A complex problem requiring a complex intervention. Community Dent Health $2011 ; 28(4): 254$.

3. Kim Seow W. Environmental, maternal, and child factors which contribute to early childhood caries: A unifying conceptual model. Int J Paediatr Dent 2012; 22(3):157-68. doi: 10.1111/j.1365-263X.2011.01186.x.

4. Ripa LW. Nursing caries: A comprehensive review. Pediatr Dent 1988;10(4):268-282. 
5. Wyne AH. Early childhood caries: A review. Indian J Dent Res 1996;7(1):7-15.

6. Hooley M, Skouteris H, Boganin C, Satur J, Kilpatrick N. Parental influence and the development of dental caries in children aged 0-6 years: A systematic review of the literature. J Dent 2012; 40(11):873- 885. DOI: 10.1016/j. jdent.2012.07.013

7. de Castilho AR, Mialhe FL, Barbosa Tde S, PuppinRontani RM. Influence of family environment on children's oral health: a systematic review. J Pediatr (Rio J) 2013;89(2):116-23. DOI: 10.1016/j. jped.2013.03.014.

8. Bozorgmehr E, Hajizamani A, Malek MT. Oral health behavior of parents as a predictor of oral health status of their children. ISRN Dentistry 2013; 2013: 741-83. DOI: $10.1155 / 2013 / 741783$.

9. Rothnie JJ, Walsh CA, Wang MJ, Morgaine KC, Drummond BK. An exploratory study of pregnant women's knowledge of child oral health care in New Zealand. N Z Dent J 2012;108(4):129-133.

10. Ashkanani F,Al-Sani M. Knowledge, attitude and practices of caregivers in relation to oral health of preschool children. Med Princ Pract 2013;22(2):167-172.

11. Schroth RJ, Brothwell DJ, Moffatt ME. Caregiver knowledge and attitudes of preschool oral healthand Early Childhood Caries (ECC). Int J Circumpolar Health 2007;66:153-167.

12. American Academy of Pediatric Dentistry. Policy on early childhood caries (ECC): classifications, consequences, and preventive strategies. Pediatr Dent. 2015; 36:50-2.

13. Al-Zahrani AM, Al-Mushayt AS, Otaibi MF, Wyne AH. Knowledge and attitude of Saudi mothers towards their preschool children's oral health. Pak J Med Sci. 2014; 30(4):720-4.

14. Lee GH, McGrath C, Yiu CK, King NM. A comparison of a generic and oral health-specific measure in assessing the impact of early childhood caries on quality of life. Community Dent Oral Epidemiol 2010; 38:333-9.

15. Casamassimo PS, Thikkurissy S, Edelstein BL, Maiorini E. Beyond the dmft: The human and economic cost of early childhood caries. J Am Dent Assoc. 2009; 140:650-7.

16. Casamassimo, P. S., Thikkurissy, S., Edelstein, B. L., \& Maiorini, E. (2009). Beyond the Dmft: The Human and Economic Cost of Early Childhood Caries. J Am Dent Assoc, Vol.140, No.6, (Jun 2009), pp. 650-7, ISSN 1943-4723.
17. Kanellis, M. J., Damiano, P. C., \& Momany, E. T. (2000). Medicaid Costs Associated with the Hospitalization of Young Children for Restorative Dental Treatment under General Anesthesia. J Public Health Dent, Vol.60, No.1, (Winter 2000), pp. 28-32, ISSN 0022- 4006.

18. Almeida, A. G., Roseman, M. M., Sheff, M., Huntington, N., \& Hughes, C. V. (2000). Future Caries Susceptibility in Children with Early Childhood Caries Following Treatment under General Anesthesia. Pediatr Dent, Vol.22, No.4, (Jul-Aug 2000), pp. 302-6, ISSN 0164-1263

19. Ismail, A. I. (2003). Determinants of Health in Children and the Problem of Early Childhood Caries. Pediatr Dent, Vol.25, No.4, (Jul-Aug 2003), pp. 328-33, ISSN 01641263

20. Finlayson TL, Siefert K, Ismail AI, Delva J, Sohn W. Reliability and validity of brief measures of oral health-related knowledge, fatalism, and self-efficacy in mothers of African American children. Pediatr Dent 2005; 27(5):422-8.

21. Al-Hosani E, Rugg-Gunn A. Combination of low parental educational attainment and high parental income related to high caries experience in pre-school children in Abu Dhabi. Community Dent Oral Epidemiol 1998; 26(1):316. doi: 10.1111/j.1600-0528.1998.tb01921.x.

22. Figueiredo MJ, de Amorim RG, Leal SC, Mulder J, Frencken JE. Prevalence and severity of clinical consequences of untreated dentine carious lesions in children from a deprived area of Brazil. Caries Res 2011; 45(5):435-42. doi: 10.1159/000330531.

23. Da Silva K. A role for the family in children's oral health. N Y State Dent J 2007; 73(5):55-7.

24. Kabil N. and Eltawil S. Reshuffling the Risk Factors of Severe Early Childhood Caries. Dent. J. 2017, 5, 4; doi:10.3390/dj5010004

25. Mani S.A., John J., Ping W.Y. and Ismail N.M. Early Childhood Caries: Parent's Knowledge, Attitude and Practice towards Its Prevention in Malaysia. https://www. researchgate.net/publication/221926006.

26. Abu Hamila NAA (2013) Early Childhood Caries and Certain Risk Factors in a Sample of Children 1-3.5 Years in Tanta. Dentistry 4:180. doi:10.4172/2161-1122.1000180

27. Abduljalil HS, Abuaffan AH (2016) Knowledge and Practice of Mothers in Relation to Dental Health of PreSchool Children. Adv Genet Eng 5: 153. doi:10.4172/21690111.1000153. 
28. Alzaidi S.S. Alanazi I.A. Abo Nawas O.M. Mulla M.A. Childhood Oral Health: Maternal Knowledge and Practice in Tabuk, Saudi Arabia. The Egyptian Journal of Hospital Medicine (January 2018) Vol. 70 (9), Page 1544-1551.

29. Ravi Kumar G, Kiran Kumar Ganji, Santosh Patil, Ahmed Alhadi, Mohammed Alhadi. Parent's Knowledge, Attitude and Practice on Prevention of Early Childhood Caries in Al jouf Province, Saudi Arabia. Pesquisa Brasileira em Odontopediatria e Clinica Integrada 2018, 18(1): 1-9.

30. Schuster, Daniel P.; Powers (MD.), William J. (2005) Translational and Experimental Clinical Research. Lippincott Williams \& Wilkins. p. 46. ISBN 9780781755658. Retrieved 29 September 2017.

31. World Health Organization. Oral Health Survey. Basic Methods. 4th ed. Geneva, Swizerland: WHO; 1997.

32. Definition of Early Childhood Caries (ECC). American Academy of Pediatric Dentistry. Pediatric dentistry 2008; $4(3): 15$.

33. Anne R Wilson, Angela G Brega, Elizabeth Campagna, Patricia A Braun, William G Henderson, Lucinda L Bryant, Terrence S Batliner, David O Quissell, and Judith Albino. Validation and Impact of Caregivers' Oral Health Knowledge and Behavior on Children's Oral Health Status. Pediatr Dent. 2016; 38(1): 47-54.

34. Oredugba F, Agbaje M, Ayedun O, Onajole A. Assessment of mothers' oral health knowledge: towards oral health promotion for infants and children. Health. 2014; 6:908-915.

35. Hiu F. L., Kok W. W.,Hai M. W., Kar Y. Y.Parental Oral Health Literacy of children with severe early childhood caries in Hong Kong. European Journal of Pediatric Dentistry .2017; 18(4):326-331
36. Anne W., Angela B.,Terrence S., William H., Elizabeth C., Karen F. Assessment of Parental Oral Health Knowledge and Behaviors among American Indians of a Northern Plains Tribe. J Public Health Dent. 2014 ; 74(2): 159-167.

37. Kamil1 M.A., El-Ameen N. M., Madkhaly S.H., Alshamarry T. H. , Hakami R. U. 3 and Nassir E. M. Knowledge and attitude of Saudi mothers towards health of primary teeth. J. Dent. Oral Hyg.2015; 7(7):107-112

38. Rafi A.thesis Togoo, Master Luqman, Atheer A. AlHammadi, Nada A. Al-Rabai, Shatha M. Ahmasani, Bayan D. Al-Qahtani. Caregivers' Knowledge, Attitudes, and Oral Health Practices for Infants Attending Day-Care Centers in Two Cities in Southern Saudi Arabia. GMJ. 2017; 6(1):35-41.

39. Dentistry AAP Policy on Early Childhood Caries (ECC): Classifications, Consequences, and Preventive Strategies. Pediatr Dent .2014; 37:50-52.

40. Kaur B Evaluation of oral health awareness in parents of preschool children. Indian J Dent Res .2009; 20: 463-465

41. Chhabra N, Chhabra A Parental knowledge, attitudes and cultural beliefs regarding oral health and dental care of preschool children in an Indian population: a quantitative study. Eur Arch Paediatr Dent .2012; 13: 76-82.

42. Reang T, Bhattacharjya H (2014) Mother's knowledge and practice regarding oral Hygiene and challenges in the prevention of dental caries of under-five children in an urban resettlement colony. Int J Med Sci Public Health 3: 76-80.

43. Kowash MB (2015) Severity of early childhood caries in preschoochildren attending Al-Ain Dental Centre, United Arab Emirates. Eur Arch Paediatr Dent 16: 319-324. 